\title{
Re-framing Pacific regional service delivery: Opportunity spaces for together and apart
}

\author{
Kabini Sanga \\ Victoria University \\ kabini.sanga@vuw.ac.nz
}

\begin{abstract}
Regionalism is a common development strategy in the Pacific region. Through it, numerous services are delivered to countries, communities and organisations. While some see regionalism as an effective and efficient strategy for the Pacific region, others point to its dismal performance. Using the experience of the Rethinking Pacific Education Initiative for and by Pacific Peoples (RPEIPP) as a regional strategy, this paper explores regional service delivery and offers a plausible way of re-framing service and delivery for conceptualizing Pacific regional strategies.
\end{abstract}

[Keywords: Pacific, regionalism, education, service, delivery]

\section{Introduction}

Regionalism is a common development strategy of service delivery in the Pacific. Historically, foreign Christian missions, colonial powers and traders had used the strategy to deliver their various services. In more recent times, Island Churches, Pacific governments, metropolitan governments, international agencies, multilateral institutions, companies, sporting bodies, professional consortia and networks have used (or are using) regional partnerships on the grounds that it is deemed to be an effective and efficient way of dealing with common issues beyond national capabilities. While exact numbers are not known, one estimate (Neemia, 1986), had put it at more than 200 regional organizations existing in the mid eighties. More recently, Asian Development Bank (2004) appeared to have used this same estimate; adding that many of these regional organizations are supported by national Pacific governments.

In these newer times, concerns are being raised of regionalism as a service delivery strategy. For instance, in conversations (at which the author was present) with two political leaders there was an expression of concern about the tendency of the regional organization to focus on itself rather than on its country members, thereby enhancing its own power and acting hierarchically towards national governments. To a more public audience, on the occasion of the $40^{\text {th }}$ anniversary of the Pacific Islands Forum (PIF), it was reported by the Pacific Islands Forum Secretariat (PIFS) (2011) that the Prime Minister of Vanuatu and Forum Chair, Hon. Sato Kilman had asked: "Where does the balance lie between service 
delivery at the national level and regional level?" His Excellency Hon. Kilman further enquired: "What is the ideal nature of the relationships between national and regional?" Within education, the governing council ${ }^{1}$ of the University of the South Pacific (USP) often wrestles with the belief that what Pacific countries do together (regionally) strengthens what individual countries do apart (nationally). Generally, the basic premise of this belief is accepted by council members. More often than not, however, such an acceptance is emotive rather than being based on sound inferences and substantiated conclusions.

While concerns are being raised, hopes for a new Pacific regionalism are being promulgated, largely by the international development community. In an Asian Development Bank (ADB) commissioned report, Grynberg, Hyndman and Siva (2005) proposed a new Pacific regionalism, "which places good governance and economic growth as its highest priorities... aimed at strengthening economic management... lowering costs and more effective regional transport and communications, and... a binding instrument based on mutual obligation involving trade, aid, and governance commitments" (p.14). According to these authors, such a strategy should ease capacity constraints for governments through increased provision of services and create economic opportunities for Pacific citizens through increased market integration. Further, in their critique of the neo-liberal bias of the new Pacific regionalism, Slatter and Underhill Sem (2010) have observed that promulgators of this new regionalism have gone ahead and proposed ideas for integration, including a regional economic and statistical technical assistance facility, a regional capacity to assist customs officials collect revenue, a regional ombudsman, a regional panel of auditors and more. The question is asked: How do we negotiate between the concerns over regionalism and the calls for a new Pacific regionalism?

In this article, I sympathise with regionalism as a partnership strategy for service delivery in the Pacific. My basic premise is that the shared values of regionalism (such as positive inspiration, collaborative affirmation and collective generosity) strengthen nations' sense of dignity, their priority positioning, creative actions and people accountabilities. I use the case of Rethinking Pacific Education for and by Pacific Peoples (RPEIPP), a regional education initiative of which I was one of the leaders as well as being the principal convener. Briefly, as a partnership strategy, the RPEIPP was initiated, led and delivered by Pacific educators and supported with a grant from the New Zealand Agency for International Development (NZAID). During the 2001-2007 funded periods, the RPEIPP-NZAID partnership formed and linked many other partnerships at different levels throughout the Pacific region. As a regional partnership strategy the RPEIPP has continued to thrive even after the cessation of its NZAID grant support.

In my analysis of the RPEIPP, I hope to show more compelling (newer, substantive, insightful) evidence of regional service delivery. By doing so, I demonstrate examples of partnerships that are symbiotic and generative; where

\footnotetext{
${ }^{1}$ Author is a member
} 
multiple relationships co-exist within a volatile and dynamic Pacific development context. In the end, I propose a plausible re-framing of regional service delivery which is based on recognition of and responsiveness to opportunity spaces for together (regional) and apart (national). But first, a brief discussion on the understandings of regionalism is necessary.

\section{Pacific Regionalism}

\section{Understanding regionalism}

The term, regionalism, is defined in a number of ways. According to Haggard (1997), regionalism is used to refer to a geographical proximity, or to economic flows and coordination, or to political-military relations. In the development literature, while the meaning of regionalism is somewhat context-bound, it is generally acknowledged that the Pacific region is unique. In some instances particularly in relation to vast countries or continents such as South America or Africa - regionalism is applied to the sub-national or more local levels (Coe, Hess, Yeung, Dicken \& Henderson, 2004). The usage of the term, regionalism, by the European Union (EU) is not as explicit. While the EU uses the term, it does so in reference to parts of Africa or certain African, Caribbean, and Pacific (ACP) regions (Michel, 2006). In the Pacific, however, regionalism always refers to a collective of nations (Asian Development Bank, 2004; ADB, 2006; ADB, 2009).

Consequently, in the Pacific region, regionalism is simply defined as "countries working together for their joint and individual benefit" (Pacific Islands Forum Secretariat, 2008, p.3). Given such a definition, three types of regionalism are used by the PIFS, as follows:

Regional cooperation-involves establishing dialogues and processes between Pacific governments. In this way, policies can still be regionally coordinated (via agreements or through dedicated regional institutions) while services (such as transport, customs, statistics) can be delivered nationally by governments.

Regional provision of public goods and services - involves taking away of a particular national service so as to provide this service collectively to countries. Examples include the University of the South Pacific (USP), the Forum Fisheries Agency (FFA) and the South Pacific Regional Environmental Programme (SPREP).

Regional integration - involves the integration of systems (primarily economic systems). Examples include the South Pacific Trade and Economic Cooperation Agreement (SPARTECA) and the Pacific Island Countries Trade Agreement (PICTA).

In the Pacific region, regional partnership initiatives usually start with regional cooperation. Some initiatives would be moved on to regional provision of public services and others to regional integration. Development agencies (donor and lenders) seem to favour ultimate regional integration (ADB, 2006; Grynberg, Hyndman \& Siva, 2005) while Pacific countries do not seem to desire full 
integration. The Prime Minister of Vanuatu and Forum Chair, Hon. Sato Kilman, for instance, has warned against full regional integration as it risks providing benefits for New Zealand and Australia at the expense of the Islands, particularly in regard to land acquisition and direction of skilled labour flows. While noting the advantages of the collective voice, Kilman cautions that fully integrating trade, economies, and communities will generate difficulties, concluding that "the key issue is to what extent [regional efforts] are making a difference to the lives of the people of the Pacific (PIFS, 2011, p.1)." In Kilman's view, "Integration will only work when we can align national and regional interests. When this is not possible then it is only right that we retain our own national approach in dealing with our needs (Ibid, p.1)."

According to the PIFS (2008), there are three tests for assessing the value of applying regional approaches to initiatives. Following a reading of PIFS, these are summarized as follows:

Market test-when the market is providing a service well, then national governments and/or regional bodies should be minimally involved.

Subsidiary test-where national/local governments can provide services well, regional bodies need only be minimally involved. As examples, primary-secondary education is generally provided by national or local authorities, thereby (historically) leaving university education to be provided by USP as a regional university.

Sovereignty test-where the effective sovereignty of a national government is compromised, regional bodies should be minimally involved. Involvement might mean a shift in the nature of the service delivered such as from policy-making to managing programmes.

It would seem that the three tests are for internal application by PIFS. I have not, however, come across any examples of such application by PIFS or other Pacific stakeholders. Nor have I sighted an example of a Pacific national government or its national stakeholders, assessing a country's membership to a regional initiative. Towards this end, countries which are interested in assessing the value of their memberships to regional initiatives (organizations or programmes) might use the International Organizations' Assessment Framework for Small Island States (Sanga \& Pollard, 2007), which was commissioned by the London-based Commonwealth Secretariat and trialed successfully in 2007 by Vanuatu and Solomon Islands.

In the Pacific region, the Pacific Plan (PP) is the principal instrument of regional service delivery. First endorsed by Pacific Heads of Government in 2005, the PP is presented as a new and innovative approach to the particular nature of the challenges faced by Pacific Island countries. The basic framework of this approach is a regional one. As an instrument for regional service delivery, the Pacific Plan is linked to international development frameworks: the 1994 Barbadors Programme of Action, the 2005 Paris Declaration on Aid Effectiveness and the 2005 Mauritius Strategy of Implementation. The Pacific Plan, however, is carefully designed to support other regional frameworks such 
as the Pacific Principles on Aid Effectiveness. Clearly the intention is that regionalism is to be driven by and serve the interests of country members.

In 2007 the Pacific Plan itself was revised by Pacific leaders, among other things, to "strengthen regional cooperation and integration" (PIFS, 2007, p.2) for certain activities, and to "clarify members' own understanding and appreciation of regionalism with a clear perception of benefits and costs" (Ibid, p.2). Again, in their revision of the Pacific Plan, leaders emphasized that regionalism "does not limit the sovereign right of Forum member countries to determine their own national goals and priorities" (Ibid, p.2).

Such justifications are expressed by Grynberg, Hyndman and Siva (2005) in their advocacy for the Pacific Plan. According to these authors, "[t] he Pacific Plan can...reinforce the effective sovereignty of governments by increasing access to higher quality services, including policy and technical services through delegating more specialized functions and by broadening economic opportunities" (p.5).

Clearly these authors suggest that regionalism is a viable option for small and isolated Pacific countries. In their view, regionalism is likely to be more sustainable. They also spoke of the idea of clubs, thus opening a door for subregional groupings such as the Melanesian Spearhead Group.

In one of the earliest studies on Pacific regionalism, Neemia (1986) speaks about regionalism as collective self-reliance where Pacific Island countries can share both the costs as well as the benefits of problems and resolutions of these. For this author, while there are conflicting national interests among partners-states and distributional conflicts over costs, regionalism offers Pacific governments a collective bargaining power for dealing with the developed world. Such a view is supported by Haggard (1997) who, in talking about regionalism in Asia, explains that among other justifications, regionalism is a distributive game between small and large players. Consequently, small countries can use regionalism to influence and establish their credibility on the global stage.

Having explored understandings of and justifications for regionalism, and after five decades of regional experience in the Pacific, it is worth considering the performance record for regionalism in the Pacific region.

\section{Performance of regionalism in the Pacific}

In a general sense, the verdict on Pacific regionalism is a mixed one. On the one hand, the University of the South Pacific, as a regional organization, is seen as a success (for example, see ADB, 2006). On the other hand, there appears to be dissatisfaction with the performance of regional strategies. This latter view is dealt with in the rest of this section in order to explain the various attributions of this poor performance.

In 2006, while commenting on complementing national development strategies in education with regional initiatives, former PIFS Secretary General, Greg Urwin, reiterated, "A regional approach should only be taken if it adds value to national efforts”(PIFS, press statement, 26 September 2006). However, by 2008 Urwin, 
still in the role of PIFS Secretary General, seemed to demonstrate impatience, urging more deep-seated regionalism, noting that "Forum member countries have given priority to cementing their national sovereignties and it was only recently that they begun [sic) to look in-depth at what benefits regionalism might bring to them" (PIFS, press statement, 12 December 2008). While successes had occurred through working together, Urwin observed that "regional cooperation is seen as additional to national priorities rather than intrinsic to them." The Secretary General acknowledged that sub-regionalism may sometimes be more appropriate than "an across the board regional approach" and, if so "we should get on with it - we are not so blessed with time and resources that we can try to force everything into one mould" (PIFS, press statement, 12 December, 2008).

The view that Pacific regional strategies have performed dismally is shared by ADB (2004) which attributed such failure to "capacity constraints, inadequate involvement of local experts, diffused agendas and growth of self serving ingroups (p.6)" supposedly at national levels. Further, it would seem that even economic performance in the Pacific region had been disappointing. This, according to $\mathrm{ADB}$, is attributed to both country-level failure and undermined effectiveness of regional cooperation due to "inadequate focus on private sector development, weak regional institutional capacity, limited transfer of skills, and lack of genuine consensus on some issues (Ibid, p.7)."

The poor performance of regional strategies can also be explained by a perceived lack of ownership by Pacific countries, as expressed below.

Despite the existence of many regional institutions, there has been little evidence until very recently that the [Pacific member countries] are taking significant ownership of the deepening and broadening of regional cooperation...nor, with the possible exception of the University of the South Pacific, do [they] hold regional institutions strongly accountable for their performance... a concern to maintain sovereignty is often given as the reason for [choosing] national approaches [over regional solutions]. (ADB, 2004, p.14)

Blaming Pacific member countries for the poor performance of regional strategies is possibly too harsh. Specifically in relation to environmental issues, the ADB (2004) acknowledges that "Development partners favor regional programmes for ease of organization and economies of scale. Yet environmental problems are ultimately solved locally, even those with global dimensions (p.76)." In another example, Mellor and Jabes (2004) explain that regional good governance programmes had not been working as effectively in the past, due to a number of issues and not because of the failures of national governments per se. For instance, these authors observe that in the Pacific, modern and traditional systems of governance coexist uneasily; yet, past regional reform strategies have not understood local contexts well. They conclude that development, as a collaborative effort by Pacific member countries and the aid community, must engage civil society and consult with local communities to work towards "integrating the modern and traditional systems of governance that will make government and the management of public resources understandable to ordinary citizens outside the elite groups that to date tend to dominate national planning 
and resource allocation decisions on economic and social development (Ibid, p.49)."

Furthermore, in line with ADB's new approach to assisting the Pacific, it is reiterated that the development process "will only yield sustained outcomes and impact if it is led by the countries themselves" (ADB, 2009, p.2). This point underscores and acknowledges the need to focus not only on what assistance is required, but how best to provide it.

The uncomfortable mismatch between the promise and performance of Pacific regionalism forms the backdrop for an examination of RPEIPP as a regional service delivery strategy.

\section{The Re-Thinking Pacific Education Initiative for and by Pacific Peoples}

In 2001, RPEIPP began as a regional education initiative developed by key Pacific education leaders and supported by the New Zealand Agency for International Development (NZAID). The initiative's institutional partners were the USP Institute of Education and He Parekereke of the Victoria University of Wellington (VUW). As stated, throughout its funded period (2001-07), and indeed afterward, RPEIPP has successfully forged partnerships with numerous regional governments, international development partners and various other stakeholders. Consequently, over a decade, many initiatives have been undertaken within institutions, in countries, within sub-regions, among professional networks and across the Pacific region. In the following section, examples of these activities and programmes at national, sub-regional and regional levels are explored briefly. It is maintained that, as a regional partnership development strategy, the RPEIPP experience provides evidence that some things are best done together (at regional or sub-regional level) and others done apart at national and local level: these may be described as opportunity spaces. Although these clearly are not mutually exclusive - most things will happen at multiple levels - the notion of opportunity spaces does highlight which purposes are best served at which levels.

\section{National activities}

During 2001-2011, a number of national activities were undertaken in Solomon Islands, Tonga, Nauru, Vanuatu, Samoa, Fiji, New Zealand, Niue and Cook Islands under the auspices of RPEIPP. The types and levels of national activities varied in each of these countries. The case of Vanuatu is used here to examine RPEIPP engagements in support of a Pacific country.

In response to a request from the Vanuatu Ministry of Education, the RPEIPP supported Ni-Vanuatu education leaders to convene a series of research workshops and a national conference in 2002. Held in Port Vila, the conference provided the opportunity for $\mathrm{Ni}-\mathrm{V}$ anuatu participants to engage in constructive debate and sharing of ideas on education to inform practice, policy and research. 
Participants included chiefs, policy-makers, teachers, students, clergy, politicians and leaders from civil society groups.

The outcomes of the Vanuatu activities were wide-ranging and included the publication of an edited book, incorporation of conference recommendations into departmental policies and linking conference ideas with teacher training, research training and resource writing. Since 2002, numerous other transformative initiatives and programmes have resulted from the Vanuatu national activities.

From a service delivery perspective, RPEIPP engagement with Vanuatu has highlighted a number of key learning points. As a means to mobilize and engage national communities in intellectual discourse, the national conference worked well, particularly because of effective contextual leadership by $\mathrm{Ni}$-Vanuatu leaders. In giving voice and encouraging participation by local people who would otherwise not participate in influencing educational policy, the approach was transformative and appropriate. By adopting a variety of sessions; being cognisant of indigenous and community ways of being, doing and knowing; conference participation was effectively enhanced. Because committee members comprised various community stakeholders, the conference was able to attract the involvement of multiple local communities, thereby strengthening cooperation, coordination, and leadership locally. The approach also was effective in establishing ownership for the ideas generated and processes used. From a service perspective, through the active presence of key Pacific regional educators, RPEIPP was able to provide Ni-Vanuatu educators with affirmation, psychological support and legitimacy, as well as intellectual stimulation and an emphatic sense of community.

\section{Sub-regional activities}

Three sub-regional engagements were undertaken under the auspices of the RPEIPP: a research project involving Samoa, Tokelau and Cook Islands; an education policy strategic planning meeting involving Solomon Islands and Vanuatu; and an education conference for Micronesia. Again, the specific natures of these sub-regional activities and the extent of RPEIPP service delivery varied. The example of Re-thinking Education in Micronesia is used to explore subregional service delivery.

Held in the Republic of Marshall Islands in 2004, this sub-regional conference attracted educational leaders from five island groups of Micronesia (Federated States of Micronesia, Guam, Marshall Islands, Northern Mariana Islands and Palau). Led by a committee of Micronesian educational leaders, this conference was also supported by a number of international stakeholders, including UNESCO, the Asian Development Bank and Resident foreign embassies, together with RPEIPP. Numerous local organisations and peoples took part, allowing for lively discussions on a wide range of topics relating to the broad theme of indigenous education.

What particular insights were obtained from this sub-regional activity as a means of service delivery? First, the Micronesia experience was effective in mobilising support for ideas, causes and priorities which have been previously sidelined. 
Second, as spaces for connectivity and positioning, this sub-regional conference was effective. Consequently, key outcomes of the conference included the local and sub-regional leadership demonstrated by educators, the establishment of an Education Commission for Micronesia, subsequent national initiatives on rethinking education in countries and states, and a number of writing and research projects. Third, a contingent of participants from the South Pacific also participated, thereby enhancing cross-fertilization of ideas and experiences across cultures, nations, sub-regions and internationally.

Generally, a sub-regional programme of this nature is effective for its motivational value to educators who are, otherwise, isolated and busy. The service delivered has been the opportunity spaces created for inspiration, connecting and positioning people and ideas.

\section{Regional activities}

During the past decade, numerous regional activities had been successfully convened under the auspices of RPEIPP; ranging from longer-term programmes to specific activities and to series of developmental initiatives. Three regional programmes are discussed as examples.

First, in 2001 a regional symposium on Pacific education brought together a select group of key educational leaders. Participants did not represent Pacific countries or governments although some were senior government officers. They came from universities, ministries of education, colleges of education, technical colleges and a non-government organization, and included thought leaders of Pacific heritage who were residents of New Zealand and Hawaii. From this regional activity and approach, having a focused meeting of able regional participants was useful for serving a specific purpose. In the time given, a cohort of busy Pacific educational leaders was able to accomplish a specific regional task, efficiently.

Second, the RPEIPP commissioned 12 regional research projects and managed these projects centrally. As many as 20 researchers, scattered in eight countries, participated. Recipients of funds included teachers, curriculum developers, education officers, teacher educators, and university lecturers. The effectiveness of this approach was mixed. On a positive note, educators throughout the Pacific welcomed having a small fund available to novice and resource-starved researchers. All funded researchers started their projects enthusiastically, collected useful data and began some analyses. One research team used its funds to undertake a country-wide research project, thereby, enhancing the country's institutional research capacity. On a not-so-positive note, very few of the research projects were completed, for a number of different reasons as explained below.

A number of lessons on regional service delivery emerged from this research project. First, managing such a strategy centrally was extremely difficult, due to a number of reasons relating to communication, administrative and accountability reporting, variable competencies, challenges of communication technologies, issues of timelines and more. We further learnt important lessons on aspects of 
implementation of tied-aid, monitoring of outcomes-based regional activities and the challenges of capacity building in varied technological, competency, organisational and political settings.

Third, RPEIPP organized a regional conference on Educational Aid in the Pacific which was jointly convened by VUW and USP in October 2003 and held in Nadi. This conference created opportunities for sharing experiences, making critical reflections and strategizing. The approach recognized that while aid has become integral to educational development within Pacific countries, it had not received adequate independent scrutiny by Pacific peoples themselves. The conference was the first regional academic and stakeholder forum on educational aid to be led by Pacific educators and held independently of governments' or donors' direction. It was, however, open to donors and other international participants.

The conference attracted Pacific teachers, government officers, researchers, community leaders, students and university academics from Guam, Hawai' $i$, Tuvalu, Papua New Guinea, Nauru, Solomon Islands, Vanuatu, Tonga, Samoa, Niue, Cook Islands, Aotearoa New Zealand, and Fiji. Senior officials from regional institutions, including the PIFS and the USP, took part. From the donor community, representatives came from the Asia Development Bank, European Union, AusAID, UNIFEM, UNICEF, JICA, and NZAID. Consultants, academics, development specialists, and educators from Australia and New Zealand also participated.

The regional conference approach was effective in a number of ways. First, the forum was motivational for Pacific participants, many of whom were isolated and often struggled in their daily work with donors, governments and consultants. Second, the approach allowed for suggesting regional strategies and agenda for attention, particularly with representatives of governments, donors, and regional institutions present. Third, the approach was successful in facilitating rigorous critique and stimulating debate through the participation of senior Pacific policy makers, regional civil servants, academics and Pacific thinkers. By including students in the forum, a new generation of leaders was able to engage with current leaders.

A number of services have been highlighted by these regional activities. First, RPEIPP had been able to provide enabling environments for useful intellectual engagements and sincere debates between national, regional Pacific and international participants. Second, RPEIPP was able to provide insightful understanding of and affirmation to local-contextual needs and challenges; and, it was able to respond effectively in its support to specific goals and priorities; in ways which were enabling to people in their contexts.

This section concludes with the following observations. As earlier stated, in the last four years (unfunded period), RPEIPP has continued to thrive as a truly regional movement. The initiative has continued to establish different partnerships at institutional, national and regional levels; thereby exerting ideological and other influences at different levels of communities. Among these have been the cross-breeding of ideas and harmonization with the PRIDE Project, 
particularly in the national sub-project programmes and activities. Moreover, in a number of countries, RPEIPP had invoked or renewed interest and further initiatives of Pacific-embeddedness of ownership, responsibility and pride. In other words, as a regional partnership strategy, RPEIPP seemed to have thrived in its contributions and influence. Questions can therefore be asked: How has RPEIPP as a regional partnership strategy worked? How has it negotiated the paradoxes of the regional and the national? What lessons has RPEIPP learnt that might inform the visioning of a new Pacific regionalism?

In the section which follows, these questions are explored, through a discussion of the experiences of RPEIPP as a regional approach to service delivery.

\section{Discussion on Regionalism}

Based on the RPEIPP experience, it is evident that as a regional partnership development strategy, some things are best done together (at regional or subregional level) and others done apart at national and local level: these may be described as opportunity spaces. While these are clearly not mutually exclusive these things will happen at multiple levels - the notion of opportunity spaces does, however, highlight what purposes are best served at which levels.

As a regional strategy, RPEIPP has focused on developing people capability, particularly of national educators, students and emerging and thought leaders. Numerous opportunity spaces for people development were created in the forms of leader and leadership development workshops, mentoring programmes and research skills development training. Consistently, all such programmes were led and delivered by Pacific regional educators themselves. Accordingly, all Pacific educators were seeking "to address major education issues at a very strategic level. The focus was very much on effectiveness - creating change" (Sanga \& Nally, 2002, p.1).

A key explanation for its effectiveness related to the ability of RPEIPP to create opportunity spaces for inspiration. Regional conferences and symposia, by their nature, provided these spaces for exploration and dialogue, for nurturing of ideas, and for incubating learning and platforms for action to support what is best done at national or local level. In other words, what we do together strengthens and enlivens what we do apart - it does not weaken, reduce or marginalize what is done apart. In this way, RPEIPP was able to foster and strengthen partnerships, relationships, leadership, and ownership. These have been achieved by generating excitement, engagement, motivation, purpose, confidence, energy, and enthusiasm; empowering people through leadership development, mentoring, support, encouragement and the utilising of Pacific processes, skills, and knowledge; fostering relationships and reducing isolation via networking and advocacy; building capacity via training and generating resources; maximising participation including mobilizing communities and building awareness; and, engaging in and influencing a unique "more moral" donor/recipient aid partnership that departs from the usual "top-down" approach (van Peer, 2008). 
RPEIPP also provided opportunity spaces for creativity. As stated, as a regional initiative, RPEIPP was donor funded but not donor driven. It was managed by a core group of Pacific experts. The strategy engaged people from national, regional and community levels and not just an elite group. Furthermore, due to the hand-picked Pacific experts' knowledge, it was understood from the outset that one approach would never be appropriate for all situations. As reported by Sanga and Crowl (2004), "Activities and events [have been] varied and flexible according to contexts" (p.13). Seen in this way, RPEIPP activities which were undertaken together (sectorally, cohort of institutions, nationally or regionally) were deliberately designed to inspire, motivate, educate, and support activities which were to be done separately (in organizations, sectors, country settings).

RPEIPP used implementation approaches which provided opportunity spaces for integration. As stated by Sanga and Crowl (2004), "The RPEIPP used different approaches to develop capacity, multi-level and cross-cultural engagement across international and national boundaries, involvement at different sectoral and educational levels as well as across a wide section of Pacific communities" (p.13). The authors further noted that "the processes have been simultaneous: national, sub-regional, and regional projects have bolstered each other; thereby allowing for flexible and varied approaches to meet diverse needs" (Ibid, p.13). Regional, national and institutional leaders were therefore able to integrate their experiences with their reflective learning; allowing for further and on-going learning to take place concurrently.

In a study (van Peer, 2008) on the impacts of RPEIPP, it was identified that the success of this regional programme was consistent over a range of evaluation reports (Sanga \& Nally, 2002; Sanga, Niroa \& Teaero, 2003; Taylor, 2003; Sanga \& Holland, 2004; Sanga \& Crowl, 2004; Taylor, Lameta \& Narayan, 2006; van Peer, 2006). This finding provides compelling evidence of the positive impacts of regional activities and actions, in addition to activities at the national level. Furthermore, these reports have noted that the RPEIPP approach has a strong focus on process - a point which is essential for effective regional partnership service delivery strategies.

Just as for other strategies, the RPEIPP regional strategy also experienced a number of challenges. According to Sanga and Crowl (2004) and van Peer (2008), these included issues of isolation/inclusion, monitoring, technology and resourcing, unrealistic timelines, heavy demands for support, capturing the discourse fully, sustaining expectations, engaging national bodies (MoEs), and transmission of philosophy. It was further acknowledged that a key challenge, requiring constant reflection, was to be aware of what was working and what had changed. According to van Peer (2008), "Innovation is needed to actively engage...national stakeholders to ensure better alignment of RPEIPP with and responsiveness to country priorities, capacities and processes" (p.16). While regional strategies are assumed to be effective for provision of support, the RPEIPP experience has shown how challenging it is to know the right kind of support and to offer this in a timely manner. Particularly in the early stages of 
national initiatives, regional support must ensure that local ownership is established and sustained.

RPEIPP's effectiveness as a regional partnership development strategy can be attributed to its ability to create opportunity spaces for connectivity. Connectivity refers to strategic relationships, networks and leveraging of resources. Through establishments of symbiotic and generative relationships within local, national, regional and global contexts, Pacific educators were able to create synergies (through networks, collaborations, teamships) with their own visions. Consequently, the further growth and expansion of leadership movements and research activities throughout the region, following the funded period of RPEIPP, are evident of successful capturing of the opportunity spaces of connectivity.

Further, it can be said that as a regional partnership strategy RPEIPP has demonstrated understanding and application of appropriate accountability. While accountability is commonly thought of merely in terms of reporting on usage of funds, it is used here to refer to a conscientious stewardship of resources. RPEIPP made considerable efforts to create opportunity spaces of accountability that included recognising, supporting, developing, and utilising indigenous skills; that regional activity can only serve some of the diverse needs of the national and local. Further, the RPEIPP approach affirmed that the purpose of outsiders' (those not primarily from the context) engagement is to enhance local structures, aid national endeavour, and to assist Pacific peoples in their local and national contexts. As stated, the RPEIPP strategy has shown that capacity is enhanced when attention is given to process considerations; funding is better spent on building capacity than maintaining services (Sanga \& Crowl, 2004; van Peer, 2008). This is achieved through focused attention to open communication, commitment to resolving issues, people and processes, Pacific ownership, aspects of time and timing, creating strong relationships, and Pacific leadership development (van Peer, 2008).

Finally, the RPEIPP experience has further showed the importance of what might be considered as 'service' from a development perspective. It would seem that besides tangible outcomes such as policy papers, research reports, conferences, training programmes and activities; or services in sectors such as education, health, the environment or immigration; a much needed service in the Pacific region is of an 'inside-out' subjective kind. On this note, RPEIPP had been able to successfully and effectively provide inspirations, ways of being, understanding and knowing; together with infusing renewed energy into people; mentoring younger educators and motivating all to act in serving their own communities.

\section{Conclusions}

There are a number of points that can be concluded about regional partnerships. Each of the following four paragraphs addresses one broadly conclusive aspect of regional partnerships and particular points within that aspect.

First, it is acknowledged that the success of Pacific regionalism to date has been compromised by tensions between national and regional priorities. However, 
although there continue to be differences in perceptions of the urgency, speed, degree and nature of Pacific regionalism, there are general agreements about certain understandings. It is agreed that in such partnerships, the regional exists to serve the national/local. As well, one-size-fits-all approaches are not appropriate in regional partnerships. Additionally, the how is as important as the what of service delivery in regional partnerships. Moreover, the participation of civil society stakeholders is essential.

Second, challenges of scale, distance and isolation often mean that nations and their representatives need specific attention and support. The regional is best placed to offer specific, innovative and needed longer-term support. Given the particular experiences of RPEIPP as a regional partnership strategy for service delivery, it would seem that a regional approach is useful for creating:

- spaces of inspiration, wherein people with multiple needs, priorities and interests might be exposed to, and develop, hopeful and hope-filled visions for their own settings;

- spaces of integration wherein diverse participants and representatives might be made more aware, might begin to articulate, and might reignite and possibly craft their own responses to contextual needs, priorities and settings;

- spaces of educational exposure via talanoa (epistemological discourses), mentoring conversations, active listening and observant learning from the ideas and support and attention.

Third, a national strategy is effective for providing opportunity spaces of creativity. At national or local levels, people might be called to design solutions, offer and explore creative breakthroughs strategically, collectively and personally. This is the level for specific attention to the how of a challenge, not the regional level. The RPEIPP experience has also shown that spaces apart (national and local levels) are more appropriate for serving the following purposes:

- for meaningful connectivity through symbiotic relationships and team building for further exploration, and where information sources, flows and leveraging can take place, be explored and enhanced;

- for creating opportunities for positioning where alignments of people, power and influence might take place, where the marginalised might be empowered and the voiceless are given voice and hope is offered to the weakest so as to make significant impacts at grass roots levels;

- as spaces of accountability, where reviews and reflections on visions, processes and varied impacts on society are explored and undertaken. Particularly at local levels, conscientious stewardship requires further education takes place from insights gained so as to inform and inspire others towards further influence and gain. 
Fourth, this discussion of the RPEIPP experience responds to Slatter and Underhill-Sem's (2010) "challenge to re-claim Pacific regionalism from the clutches of neoliberalism..." (p.20). The challenge is responded to by providing a plausible lexicon from which newer discussions about Pacific regional partnership strategies might be launched. I have concluded that in Pacific regional partnerships, spaces together (regional) are principally, the spaces for inspiration of partners, for their integration of ideas, for their educational exposure and their specific mentorship and support. While not mutually exclusive, I further conclude that spaces apart (national, local) are primarily the spaces for partner creativity, their own positioning, their connectivity and accountability to their multiple stakeholders.

Finally, I note that for Pacific Islands countries, regional partnerships as a service delivery strategy are essential. For this development strategy to work, however, it has to first affirm the autonomy, priorities and aspirations of each national partner, before it embraces their shared identities. Moreover, Pacific regional partnerships of the future require newer understandings of service and, consequently, of service delivery. In this article, I have suggested that the critical regional service is a more inside-out subjective one (as in inspiration, integration, mentorship etc.) than has been traditionally understood. I further propose that regional partnerships facilitate such service through the purposeful creation of opportunity spaces. Within such spaces, partners might create symbiotic and generative relationships, which, as multiple and multi-leveled networks, can coexist mutually and by choice. In this way, the together (regional) exists to serve the apart (national).

\section{References}

Asian Development Bank (2003) Country Strategy and Program 2004-2006: The Pacific, Manila: ADB.

Asian Development Bank (2004) Responding to the priorities of the poor: A Pacific strategy for the Asian Development Bank, Regional Cooperation and Integration Strategy. Manila: Asian Development Bank.

Asian Development Bank (2009) ADB's Approach to Assisting the Pacific (2010-2014). Manila: Asian Development Bank.

Coe, N., Hess, M., Wai-chung, Y., Dicken, P. \& Henderson, J. (2004) Globalizing regional development: A global production networks perspectives. Wiley: New York.

Grynberg, R., Hyndman, M. \& Silva, S. (2005) Towards a New Pacific regionalism, Manila: ADB.

Haggard, S. (1997). The Political Economy of Regionalism in Asia and the Americas. In E. Mansfield \& H. Milner, (Eds.). The politics of regionalism, (pp.20-49). New York: Columbia University Press.

Mellor, T. \& Jabes, J. (2004) Governance in the Pacific: Focus for action 2005-2009. Manila: ADB.

Michel, L. (2006) Compendium on development cooperation strategies. Luxembourg: European Commission.

Neemia, U. (1986) Cooperation and Conflict: Costs, benefits and national interests in Pacific regional cooperation. Suva: USP Institute of Pacific Studies.

Pacific Islands Forum Secretariat, (2008) The Pacific Plan. Fiji: Suva. 
Pacific Islands Forum Secretariat, (2007) Pacific principles on aid effectiveness. PIFS: Suva.

Pacific Islands Forum Secretariat, (2011) Pacific regionalism: Past, present and future. Retrieved From www.forumsec.org

Ravenhill, J. (2003) The new bilateralism in the Asia Pacific. Third World Quarterly, 24(2), 299-317.

Sanga, K. \& Nally, T. (2002) Rethinking development practice. Paper presented at the $3^{\text {rd }}$ biennial conference of the International Development Studies Network of Aotearoa New Zealand. Retrieved from www.devnet.org.nz/conf2002/index authors.html

Sanga, K., Niroa, J. \& Teaero, T. (2003) Rethinking the rethinking of Pacific education, Wellington: School of Education, Victoria University of Wellington.

Sanga, K. \& Holland, R. (2004) Envisioning future development partnerships. Paper presented at Devnet International Development Studies conference, Auckland University, New Zealand.

Sanga, K. \& Pollard, B. (2007) An assessment framework for small states. Report to the Commonwealth Secretariat, Suva: University of the South Pacific.

Slatter, C. \& Underhill-Sem, Y. (2010) Re-claiming Pacific Islands regionalism: Does neoliberalism have to reign? Paper presented at Global Development Network, Prague. Retrieved from www.dgnet.org/cms/conference/papers/Slatter.pdf

Taylor, L. (2003) Rethinking Pacific education initiative: A critical friend's report on progress. Unpublished report to RPEI Advisory Board. Wellington: He Parekereke.

Taylor, L., Lameta, E. \& Narayan S. (2006) Mid-term evaluation of the Pacific Regional Initiatives for the Delivery of Basic Education (PRIDE) Project. Retrieved from www.forumsec.org/UserFiles/File/PIFS_06_FEDMN_06_MTE_REPORT\%281\%29.pdf

van Peer, L. (2006) Catching the Vision: Re-thinking Pacific Education Initiative - An exemplar for future development practice? Wellington: Victoria University of Wellington, Faculty of Education.

van Peer, L. (2008) Extending spheres of influence: An impact assessment of the Rethinking Pacific Education Initiative. Prepared for the Symposium on Rethinking RPEIPP, The University of the South Pacific, Suva, May 12-14. 